\title{
The Existential-Spiritual of Development of Elderly: Thematic Review \& Islamic Interpretation of al-Ashr
}

\section{Oktarizal Drianus'}

${ }^{1}$ IAIN SAS Babel

Korespondensi

oktarizaldrianus@gmail.com

\begin{abstract}
This article aims to explore various literatures on spiritualexistential development in the elderly. Initial exploration of this issue is considered important given the increasing structure of ageing population in Indonesia. This population, if not managed properly, will become a pathos structure. The author conducted thematic analysis to find the main themes of spiritual development issues faced by the elderly. The analysis technique is carried out from compiling the code, determining the initial code, to creating the theme presentation and visualizing the theme. Several themes that are considered as general issues in the spiritualexistential development of the elderly, include: 1) The dynamics of spirituality which include: disconnection versus a focus on religious activities, a more honed listening ability, to a greater wisdom on the various phenomena that surround it; 2) Reflection on existential themes in the elderly, such as: talk of the fate he went through, the death that would come to him, the suffering that made him strong, the struggles that made him strong, and the mistakes of the past; 3) The tasks of the spiritual-existential development of the elderly such as: strengthen the belief to Allah, doing higher quality goodness (amal shaleh), mutual wills in truth and patience.
\end{abstract}

\section{KEYWORDS:}

The dynamics of spirituality, Elderly, Spiritual-existential development, Thematic analysis. 


\begin{abstract}
Abstrak
Artikel ini bertujuan untuk mengeksplorasi berbagai literatur tentang perkembangan spiritual-eksistensial pada lansia. Eksplorasi awal tentang isu ini dianggap penting mengingat struktur populasi lansia semakin meninggi di Indonesia. Populasi ini, jika tidak dikelola dengan baik, justru akan menjadi struktur yang pathos. Penulis menggunakan thematic analysis untuk menemukan tematema utama tentang isu-isu perkembangan spiritualitas yang dihadapi lansia. Teknik analisis dilakukan dari menyusun kode, menentukan initial code, sampai membuat pementaan tema dan visualisasi tema. Beberapa tema yang dianggap sebagai isu umum perkembangan spiritualeksistensial lansia, antara lain: 1) Dinamika spiritualitas yang meliputi: keterputusan vs. fokus pada aktivitas keagamaan, kemampuan mendengarkan lebih terasah, hingga kebijaksaan yang lebih atas beragam fenomena yang mengitarinya; 2) Perenungan atas tema-tema eksistensial di masa lansia seperti: pembicaraan tentang nasib yang dilaluinya, kematian yang akan mendatanginya, penderitaan yang justru membuatnya tegar, perjuangan yang membuatnya kuat, dan kesalahan di masa lalu; 3) Tugas-tugas perkembangan spiritual-eksistensial lansia seperti: meningkatkan kepada Allah, melakukan kebaikan yang lebih berkualitas (amal shaleh), saling wasiatmewasiatkan dalam kebenaran dan kesabaran.

\section{KATA KUNCI:}

Dinamika spiritualitas, Lansia, Perkembangan spiritualeksistensial, Analisis tematik.
\end{abstract}




\section{1 | Pendahuluan}

Struktur populasi lansia (ageing population) semakin meninggi di Indonesia selama dekade akhir [1,2]. Fakta kerasnya dapat dilihat dari grafik statistik penduduk Indonesia dimana sumbu lansia semakin menumpul. Tanda "penumpulan grafik" ini mengisyaratkan bahwa Indonesia sedang mengalami bonus demografis [3]. Bonus demografis pada porsi lansia ini menjadi tantangan tersendirijika tidak dikelola dengan baik dan terencana. Pengelolaan yang buruk atas populasi lansia (ageing population) ini dapat memunculkan masalah-masalah diantaranya, seperti: pengangguran, kesehatan, harga diri dan status sosial menurun, depresi, problem tubuh dan disfungsi seksualitas [4], dan sebagainya.

Akan tetapi, ada salah satu perkembangan dalam diri lansia yang sama sekali tidak linear dengan degradasi tubuh dan penuaan, yaitu perkembangan religious dan spiritual [5]. Peningkatan ini sejalan jika kita menggunakan data jama'ah haji di Indonesia. Pada 2019, 63\% terdiri dari lansia [6].

Pada beberapa negara dengan masyarakat religius, seperti Indonesia, perkembangan spiritual berkembang unik dibandingkan dengan negara dengan basis sekuler. Spiritualitas terbukti mempunyai peran signifikan bagi kehidupan positif lansia [7].

Dalam literatur psikologi maupun kajian konseling lansia, spiritualitas menjadi variabel pamungkas dalam kemampuan bertahan hidup lansia. Temuan-temuan penelitian terdahulu menunjukkan bahwa: spiritualitas berperan positif bagi kesejahteraan rohani (spiritual well-being) lansia [8], spiritualitas merupakan coping bagi lansia penderita penyakit gagal jantung [9] dan penyakit berat lainnya [10-12], spiritualitas dapat mendorong gaya hidup yang lebih sehat bagi lansia [13], spiritualitas berkorelasi kuat dengan penerimaan diri, kebahagiaan, dan kontrol diri lansia [14].

Lansia, merupakan usia senja yang tidak lagi muda. Beraneka ragam dunia telah hampir dikecapnya. Manis dan pahit, keringat peluh telah terperas begitu banyak untuk mencapai masa usia ini. Suatu masa yang jika diteropong dengan perspektif well-being justru mencapai ultimate experience. Ini adalah masa keemasan spiritual.

Pandangan psikologis yang sematamata kognitif dan fisik tidak lagi memadai. Prinsip linieritas akan meringkus konsep lansia dan menjebak kita pada asumsi diskriminasi bahwa lansia tidak berdaya [15]. Pendekatan yang lebih dekonstruktif, tidak sekedar biologis-matematis perlu diajukan. Kemungkinan-kemungkinan pandangan mengenai perkembangan spiritual lintassumber mesti dipertimbangkan. Oleh karenanya, dalam rangka dekonstruksi tersebut, tulisan ini mencoba melihat sisi perkembangan spiritualitas pada manusiamanusia yang berada dalam rentang "senja”.

Selain itu, tinjauan spiritual pada lansia, merupakan ciri khas yang cenderung mengalami peningkatan dibandingkan dengan aspek lainnya. Oleh karenanya, Berdasarkan issue dan tinjauan kepustakaan di atas, maka tulisan ini bertujuan memberikan deskripsi mengenai perkembangan spiritualitas lansia dari sudut pandang psikologi eksistensial dan kemudian 
diintegrasikan dengan Islamic studies, terutama tafsir surah al-Ashr.

\section{2 | Metode}

Tulisan ini merupakan jenis kajian kepustakaan (library research) dengan pendekatan integrasi antara psikologi eksistensial dan Islamic studies, terutama pendekatan tafsir. Analisis data menggunakan analisis tematik (thematic analysis) dengan tahapan sebagai berikut: a) memahami data, dalam hal ini penulis berusaha memahami topik utama mengenai perkembangan spiritual-eksistensial lansia dari berbagai lensa disiplin dan teori yang ada; b) menyusun kode, penulis menentukan keyword yang dapat dianggap sebagai initial code; c) mencari tema, penulis membuat thematic map terhadap tema-tema utama yang dianggap relevan dengan isu perkembangan spiritual-eksistensial lansia [16].

\section{3 | Perkembangan Eksistensial dan Spiritualitas Lansia}

Tema besar psikologi perkembangan terkait dengan lansia (endings) adalah death, dying, and grieving $[17,18]$. Lansia yang dimaksud dalam tulisan ini dimulai dari lansia yang masuk dalam kategori youngest-old sampai oldest-old ( 65 tahun sampai 85 tahun ke atas) [19]. Karakteristik perkembangan lansia secara umum dalam literatur psikologi merupakan periode kemunduran (fisik), penyesuaian yang buruk (dalam hal tertentu, misalnya kesehatan). Namun, dalam hal keagamaan, terjadi peningkatan dalam hal toleransi, keyakinan, dan pelaksanaan ibadat keagamaan [20].

Hal ini senada dengan pandangan bahwa bahwa di usia lansia, biasanya mereka mengalami suatu pengalaman dan masa yang disebut dengan the religious age parexcellence [21]. Pendapat-pendapat ini hendak mengatakan bahwa perkembangan spiritual yang tercermin dalam pengalaman religius tidak mempunyai linieritas simetris terhadap penurunan-penurunan aspek lainnya. Memang, ada beberapa lansia yang menurun secara spiritual. Akan tetapi, beberapa penelitian menunjukkan bahwa religiusitas lansia lebih bertahan dan stabil [22-27].

Salah satu issue yang utama dalam kajian perkembangan lansia, yaitu kesadaran untuk menghadapi kedukaan dan kematian (grieving and death) [17,18]. Ada banyak cara dalam menanggapi dan memaknai kematian pada lansia. Hal ini tergantung dengan lingkungan keluarga, sosial, bahkan pengaruh media. Akan tetapi, secara eksistensial, kematangan spiritualitas sangat menentukan dalam memberi makna terhadap kematian ini. Di Amerika, didirikan center atau program khusus dalam coping strategies terhadap kematian [18]. Hal ini tentunya baik, namun masih segmented. Dengan kata lain, tidak semua lansia dapat mengikuti program ini. Apalagi jika dikaitkan dengan negara-negara dunia ketiga yang notabene infrastruktur sistem caring terhadap lansia yang belum memadai terkait isu ini.

Berkaitan dengan masalah lack of caring system di negara dunia ketiga di atas, tawaran psikolog yang American-centris ini kadangkadang tidak relevan jika dikaitkan dengan 
masyarakat-masyarakat pinggiran. Solusi Santrock terlalu borjuis. Akan tetapi, kerangka yang diberikan cukup membantu dalam membuat peta tematik mengenai perkembangan lansia dalam menghadapi kematian.

Salah satu model yang dapat dijadikan peta konsep, yaitu mengenai tahapantahapan sikap menghadapi kematian yang sangat populer di Amerika oleh Kübler-Ross yang menyatakan bahwa ada lima tahap [28], yaitu:1) denial and isolation, adanya penolakan terhadap kematian; 2) anger, kemarahan dalam arti mempertanyakan mengapa harus dia yang diambil, bukan yang lain; 3) Bargaining, penundaan kematian dengan melakukan tawar-menawar dengan Tuhan; 4) depression, merasa tertekan dan biasanya dirundung kedukaan, misalnya merasa takut berpisah dengan orang-orang yang dicintai; 5) acceptance, penerimaan disertai keikhlasan yang mendalam, penuh dengan kesadaran.

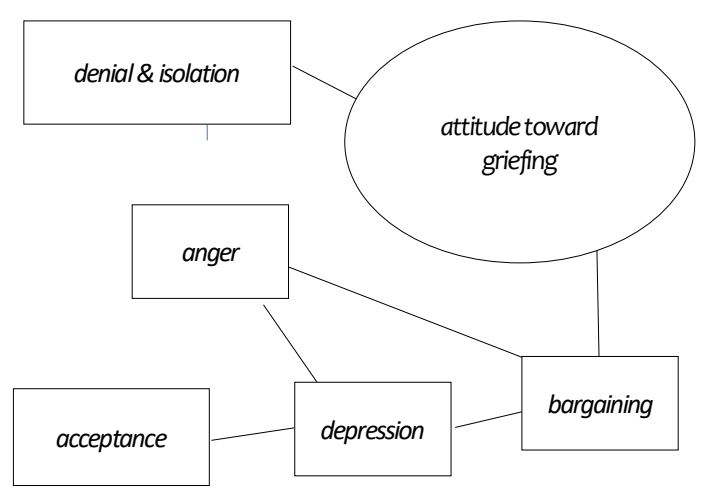

Gambar 1. Thematic map sikap lansia menghadapi kematian menurut Elisabeth Kübler-Ross

Kelima tahap Kübler-Ross ini dapat diperkuat dengan peta tematik dinamika koping lansia menghadapi kematian (coping with the death) yang biasanya melanda lansia, diantaranya: 1) communication with a dying person; 2) Grieving; 3) Making sense of the world; 4) Losing life partner; 5) forms of Mourning [18]. Kelima jenis koping ini merupakan reaksi umum para lansia berdasarkan studi empiris yang dilakukan di Amerika dan Eropa.

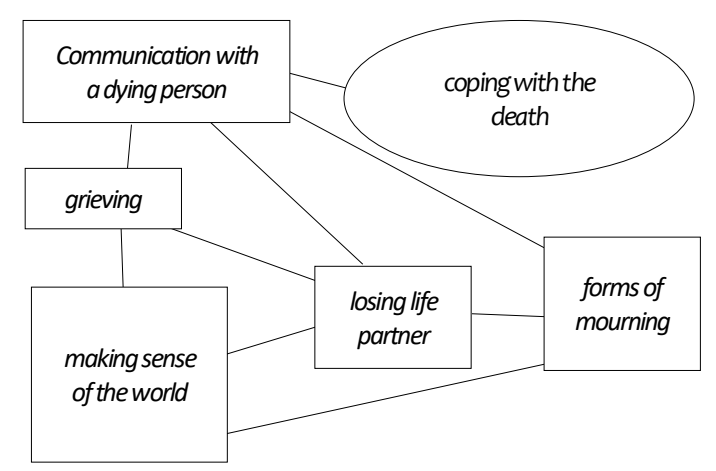

Gambar 2. Thematic map koping lansia terhadap kematian menurut Santrock

Terkait dengan perkembangan spiritual, hirarkisasi Kübler-Ross hendak menunjukkan bahwa tahap terakhir merupakan tahap puncak dan paling rasional. hal ini didasarkan pada kesadaran bahwa kematian merupakan sesuatu yang inevitable, tidak terelakkan. Spiritualitas memainkan peranan penting pada tahap dimana seorang lansia mampu untuk merelakan diri dan merasa ikhlas dan memang sudah selayaknya sebagai makhluk ia kembali kepada Penciptanya.

Kelima jenis coping ini merupakan generalisasi atas temuan lapangan dalam rentang penelitian yang panjang. Akan tetapi, terdapat beragam cara yang tergantung pada individu dan kultur yang melingkupinya. Namun, pemetaan Santrock dan Kübler-Ross paling tidak dapat menjadi titik pijak awal yang penting dalam melihat bagaimana koping spiritualitas dalam cara-cara 
menghadapi kematian tersebut. Selain itu, butuh penelitian yang berbasis budaya untuk mendapatkan variasi coping sesuai dengan konteks lansia tinggal. Misalnya, di Jepang, para istri samurai yang ditinggalkan sangat sedikit mengalami jenis koping seperti yang disebut Santrock. Para istri samurai justru memberikan ekspresi "senyuman" ketika berduka ditinggal suaminya. Senyuman tersebut sebagai bentuk sikap rela dan mencerminkan keikhlasan [29,30].

\section{1 | Agama dan Spiritualitas Lansia}

Kelima tahap ditawarkan oleh KüblerRoss di atas mengisyaratkan suatu penerimaan diri yang penuh dengan totalitas terhadap kematian. Tema kematian menjadi positif apabila didekati dengan spiritualitas yang tinggi. Oleh karenanya, pada bagian ini akan dijernihkan terlebih dahulu mengenai kekacauan pemahaman mengenai agama dan spiritualitas yang terkadang terjadi tumpang-tindih.

Demi membedakan secara distingtif diantara keduanya, maka perlu didudukkan dulu makna semantiknya. Agama, baik yang berasal dari kata religion ataupun religio, sama-sama mengakar pada bahasa latin yaitu religare, berarti “mengikat kembali”. Agama mengikat perlbagai unsur seperti manusia, alam, kepada Tuhan [31]. Pada pengertian ini, agama merupakan suatu sistem aturanaturan yang mengikat.

Akan tetapi, dalam bahasa Inggris, religion berarti 1) keyakinan kepada Tuhan atau kekuatan supramanusia untuk disembah sebagai pencipta dan penguasa alam semesta; 2) sistem kepercayaan atau peribadatan tertentu [32]. Adapun dalam bahasa Arab, agama dinisbatkan kepada kata , kata ini dapat berarti dibaca din, yang artinyamenguasai, menundukkan, patuh, dan penyerahan diri. Melalui pemahaman semantik ini, agama dapat dilihat terhadap dua pihak yang satu menguasai, mengatur dan pihak yang diatur. Ada keterikatan antara dua pihak, dalam hal ini Tuhan dan ciptaanNya [33,34].

Berdasarkan pemahaman di atas, dapat disimpulkan bahwa agama merupakan suatu sistem mengikat yang mengatur manusia dan ciptaan-Nya yang lain agar dapat menjalani kehidupan dengan penuh ketundukan, kepatuhan, dan kepasrahan diri kepada Sang Pencipta.

Spiritualitas menurut Schleiermacher merupakan "sensibility and taste for the infinite" [35]. Hal ini senada dengan James yang menyebutnya sebagai religious experiences. Dari definisi ini, dapat dipahami bahwa agama lebih sebagai "search for significance in ways related to the sacred" dan spiritualitas lebih sebagai "search for the sacred" [36]. Lebih lagi, spiritualitas merupakan "most central subjective function of religion" dan sebagai "heart and soul of religion" [37].

Pembedaan yang lebih jemih dan jelas terlihat dalam mutiara hikmah dalam kitab AlHikam yang dirujuk sebagai salah satu kitab besar dalam tradisi spiritual Islam. Pada mutiara no. 10 disebutkan bahwa:

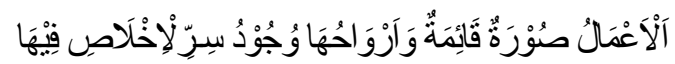

(amal ibadah laksana merupakan luarnya saja, ikhlaslah yang memberikan ruhnya), yang mengungkapkan bahwa amal ibadah hanyalah bentuk luar/fisiknya saja dari keberagamaan, spiritualitaslah yang 
memberikan ruh pada amal tersebut [38]. Menjalani agama tanpa spiritualitas seperti kesabaran, rasa takut dan harap, kecintaan, kerinduaan, cinta hanyalah bagaikan bentuk tanpa esensi apapun [39].

\section{2 | Lansia dan Spiritualitas}

Dari uraian di atas, pemahaman yang perlu dipegang bahwa agama dan spiritualitas bukan sesuatu yang terpisah [40]. Agama dan spiritual merupakan satu entitas. Akan tetapi, apabila agama menyangkut aturanaturan, batasan-batasan yang lebih objektif tentang mengatur manusia dan alam terhadap Tuhannya, maka spiritualitas merupakan ruh dalam beragama. Spiritualitas sebagai "a human capacity for relationship with that which transcends sense phenomena" [41]. Spiritualitas lebih mengacu pada subjektivitas dan pengalaman religius seseorang dalam ruang yang paling rahasia dan intim kepada Tuhannya.

Berkaitan dengan perkembangan pada lansia, spiritualitas dan pengalaman religius memberikan kehangatan, ketentraman, dan kesejukan dalam menghadapi kematian. Lansia dengan spiritualitas yang tinggi memandang kematian sebagai perjumpaan yang telah lama diidam-idamkannya dengan sang Kekasih. Pada tradisi tasawuf dalam Islam, keintiman hamba dengan Tuhannya layaknya hubungan percintaan yang bergelora [42]. Pada masa lansia, segala sekat-sekat dan rintangan-rintangan terhadap penglihatan mata batin menjadi lebih terang benderang.

Biasanya pada lansia, hasrat, keinginan duniawi, sudah mulai berkurang baik karena fisik maupun psikologis. Hal ini justru menguntungkan dalam dunia spritualitas mengingat segala hasrat tersebut berasal dari hawa nafsu. Spritualitas Islam mengumpamakannya dengan "hijab" (veil) yang dapat menutup mata batin kita melihat realitas terdalam dari suatu peristiwa [43].

Memang, harus diakui bahwa menakar secara clear-cut pengalaman spiritual seorang apalagi pada lansia -yang telah melewati perjalanan panjang pengalaman religiusbukanlah perkara mudah. Ada beberapa pandangan yang sudah umum dari teori gerontologi yang mengaitkan spiritual dengan lansia [44]. Beberapa akan diuraikan sebagai berikut:

1. Disengagement Theory

Cumming dan Henry berasumsi bahwa antara lansia dan masyarakat lebih berguna apabila adanya pengasingan terhadap aktivitas yang sebelumnya terlibat. Berdasarkan teori ini, dalam hal spiritual, keterpisahan dengan masyarakat dapat membuat lansia menjadi lebih fokus dan siap dalam menerima kematian dan menjalankan aktivitas keagamaan [44].

2. Activity Theory

Havighrust mengajukan antithesis terhadap disengagement theory. Lansia justru lebih siap menghadapi akhir hayatnya jika tetap terikat pada aktivitas-aktivitas dan melakukan interaksi sosial [44]. Kaitannya dengan spiritual, adanya power of listening ear merupakan salah satu modal sosial yang akan diperoleh dari aktivitas-aktivitas yang dilakukan pada praktik sehari-hari lansia.

\section{Continuity Theory}

Senada dengan activity theory, teori ini berasumsi bahwa penuaan menjadi lebih lambat jika tetap terhubung dengan aktivitas 
sebelumnya, interaksi mesti harus tetap dijaga dengan baik. Continuity maksudnya bukan tanpa perubahan, akan tetapi simply that occurs in the context of considerable continuity [44]. Ada kontinuitas internal yang dialami menurut pandangan ini. Kaitannya dengan spiritualitas, ada proses becoming yang membuat spiritualitas menjadi lebih baik dan matang.

\section{Social Exchange Theory}

Menurut teori ini, ada interaksionalisme-simbolik antara person dan lingkungannya. Semakin tua, hendaknya semakin pandai bergaul dan menyesuaikan diri dengan sekitar. Berkaitan dengan spiritualitas, idealnya lansia memiliki wisdom of life, sehingga pemaknaan terhadap situasi menjadi lebih penuh arti [44].

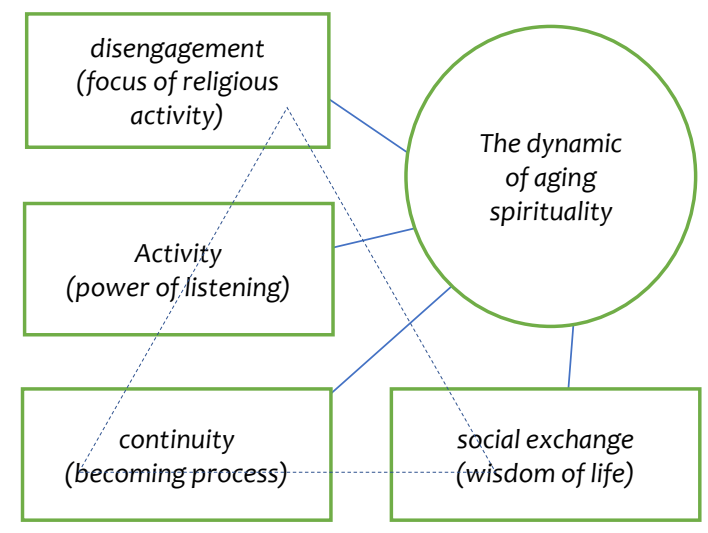

Gambar 3. Thematic Map dinamika spiritual lansia perspektif gerontology

Bertalian dengan pandangan di atas, gerontology theory menemui banyak kritik yang mendasar. Terutama pada penekanannya terhadap person dan society. Hal ini dipandang masih sangat socially, terutama tampak kelemahannya dalam melihat spiritualitas secara lebih dalam. Teori ini hanya menyajikan permukaan dan bagian eksternal dari spiritualitas. Oleh karenanya, pada bagian selanjutnya akan dicoba untuk melihat spiritualitas lansia dari dalam, yaitu secara eksistensial dan salah satunya pendekatan studi agama.

\section{4 | Lansia dalam Panorama Spiritual Well-Being}

Pembahasan dalam tinjauan psikologi perkembangan secara umum telah diuraikan di atas, walaupun dengan kapasitas yang terbatas. Tinjauan lainnya yang layak diajukan adalah tinjauan dari spiritual well-being. Kajian dari perspektif ini cukup menarik mengingat adanya integrasi antara kajian psikologi, filsafat, dan studi agama.

\section{1 | Spiritual-Eksistensial Lansia}

Adapun menelisik sisi spiritual dari sudut pandang philosophy of existential berarti mencerap makna subjektif yang dihidupi dan dihayati oleh lansia. Hal ini menjadi menarik mengingat pengalaman spiritual subjektif tiap-tiap orang berbeda. Pengalaman meaning of life ini dibungkus dalam nuansa spiritual oleh orang-orang yang sudah memasuki tahap senja ini. Hanya kekuatan spiritual lah yang membuat pemaknaan akan hidup di masa lansia ini menjadi begitu menggairahkan, damai, dan diterima dengan hati yang sangat lapang.

Mengenai spiritualitas-eksistensial ini, filosof Jerman-Swiss, Karl Jasper menawarkan penerangan eksistensial yang dapat meneropong fenomena spiritual manusia pada usia senja. Jaspers, menyebutkan Allah dengan Existenz, sedangkan manusia dengan Dasein (beingthere) $[45,46]$. Keterhubungan yang Ilahi dengan manusia ini melalui dunia yang selalu 
memiliki situasi-situasi batas yang disebutnya sebagai Grenzsituationen (ultimate situation) [47].

Situasi-situasi batas inilah yang mempunyai kontribusi dalam psikologi perkembangan pada lansia. Jaspers memaknai situasi batas ini dengan nasib, kematian, penderitaan, perjuangan, dan kesalahan [46]. Tema-tema ini menjadi tema penting dalam psikologi perkembangan lansia[18].

Perihal beragama dalam pengertian subjektif, berarti mempertanyakan eksistensi Allah dalam kehadiran dan keintimannya dalam setiap situasi yang dialami manusia. Pada saat menghayati sampai memutuskan terhadap suatu peristiwa, sebenarnya manusia tidak sendiri. la justru berhadapan langsung dalam ruang yang intim dan ekslusif dengan yang Transenden, yang Ilahi. Berikut akan diulas secara singkat bagaimana manusia berkesistensi, berhadap-hadapan secara personal dengan llahi dalam situasisituasi batas tersebut. Tema-tema ini yang dalam psikologi perkembangan lansia coba untuk dihadapi.

1. Nasib

Situasi yang paling umum-historis adalah nasib. Nasib (fide) merupakan fakta historis [46]. Proses menjadi tua adalah faktisitas historis yang tidak terelakkan. Pencerahan eksistensial yang ditawarkan adalah kita/manusia/lansia merupakan satu kesatuan dengan nasib. Nasib buruk dan nasib baik adalah "milik saya". Suatu keintiman yang llahi menampakkan diri di hadapanku. Saya dapat mencintainya atau mencoba untuk menolaknya. Menurut Jaspers, hanya kemungkinan pertamalah yang memungkinkan untuk berkembang lebih baik.

\section{Kematian}

Fakta abstrak namun sesuatu yang dialami oleh setiap orang adalah kematian. Kematian sesama, kekasih, saudara, merupakan luka paling berat yang mungkin diderita. "setiap orang meninggal sendirian". Keterpisahan karena kematian ini membuka "retak" dalam Dasein [45]. Keretakan Dasein ini justru menghadapkannya kepada yang Transenden. Seluruh hidup saya merupakan persiapan untuk kematian. Heidegger [48], menyebutnya sebagai dasein-zum-tode, ada yang menuju mati. Kematian antar satu orang dengan yang lainnya tidak mirip, ia unik. Kematian merupakan jalan yang diberi oleh yang Ilahi "hanya untuk saya".

\section{Penderitaan}

Segala penderitaan termasuk sakit, rasa putus asa, rasa disisihkan memberikan kesempatan untuk berkembangnya eksistensi. Apabila ia menghadapi penderitaannya, spiritualitas akan tumbuh melalui hal ini, ketika mengalami penderitaan, manusia lebih mudah menjadi dirinya sendiri [47]. Manusia yang tidak pemah menderita adalah manusia yang dangkal. Penderitaan adalah suatu misteri besar. Kita dapat menjadi manusiawi ketika kita terlibat dengan penderitaan orang lain. Namun, paradoksnya kita menjadi tidak manusiawi ketika penderitaan itu menimpa kita.

\section{Perjuangan}

Perjuangan disini bukanlah perjuangan dalam arti struggle for survive, Jaspers menyebutnya dengan Liebender Kampf, perjuangan berdasarkan cinta kasih [46]. Berkaitan dengan perkembangan spiritual, 
perjuangan ini lebih kepada bagaimana perjuangan dalam memupuk cinta kasih kepada yang Ilahi beserta dengan ciptaannya, manusia dan alam. Perjuangan ini tidak bisa selesai, melainkan continuity becoming. Ketidaktaatan dalam perjuangan menimbulkan kesombongan, bahkan keputusasaan.

\section{Kesalahan}

Tidak ada satu manusia pun yang tidak pernah melakukan kesalahan. Salah satu bentuk kelapangan atas kesalahan adalah bertanggungjawab. Oleh karenanya, kesalahan itu selalu bersifat mendewasakan. Manusia belajar bijak melalui kesalahankesalahannya. Kesalahan mengingatkan manusia agar mengetahui bahwa "aku selalu retak dalam kesempurnaanku”. Hanya dengan mengambil jarak inilah, kesalahan dapat menjadi mutiara yang indah.

Tinjauan eksistensialis di atas, jika dikaitkan dengan perkembangan spiritual lansia, membuat hidup lebih bermakna. Salah satu penyakit masyarakat modern, terutama ketika memasuki usia senja adalah hilangnya kebermaknaan hidup ini. Masa senja merupakan masa pencerahan penuh akan kesadaran antara diri, orang lain, alam, dan llahi. Seberapapun hidup telah diperas diwaktu 2/3, namun hal itu tetaplah kehidupan. Setiap kehidupan yang layak adalah kehidupan yang disambut dengan ja sagen, mengatakan “iya” kepada kehidupan.

Kelapangan jiwa seperti ini membuka tabir-tabir selubung yang selama ini menutup diriterhadapyang Existenz, yang Ilahi $[46,47]$. Spiritualitas pada masa senja, merupakan spiritualitas yang matang, bijak, dan mengakar ke bawah serta menjulang ke langit. Tidak ada puncak spiritualitas yang terjadi selain pada masa keemasan senja ini. Menghadirkan yang llahi, menatapnya dengan intim dan cinta kasih yang bergelora merupakan ciri kematangan iman. Bereksistensi di masa senja berarti menerima cahaya dari kehadiran yang Ilahi.

\subsection{Tahap Spiritual Lansia dalam Temporalitas}

Hidup manusia terbentang dengan apa yang disebut Santrock dengan perentangan hidup (life span). Oleh karenanya, perkembangan spiritual manusia terbentang dalam "masa hidup" tersebut. Spritualitas merentang dalam temporalitas. Spiritual bukanlah hal yang terjadi begitu saja. Spritual bagaikan menanam benih sekian lama, kemudian tumbuh subur di waktu senja hidupnya. Spritualitas dalam temporalitas ini dengan cerdas dibesut oleh sufi Islam Ibnu A'thaillah as-Sakandari dalam al-Hikam mutiara no. 11 [38], atau yang sering disebut dengan Syair Idfin:

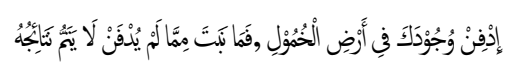

"Sembunyikan wujudmu pada tanah yang tak dikenal, sebab sesuatu yang tumbuh dari biji yang tak ditanam tak berbuah sempurna"

Spiritualitas merupakan ruh yang mengakar kuat yang buahnya bermanfaat bagi kemanusiaan. Perkembangan spiritual yang matang pada usia senja, biasanya merupakan hasil pengolahan dan pemeliharaan yang merentang dalam selama waktu hidup. Spiritualitas merupakan gelora subjektif yang dialami, bukan hanya pengetahuan kognitif. Ada totalitas dalam spiritualitas. 
Berdasarkan pemahaman spiritualitas di atas, tahap penanaman spiritual tersebut tercermin dalam tiga tahap yang diajukan oleh Filosof sekaligus Teolog dan Psikolog Denmark, Soren Kierkegaard, yaitu tahap estetis, tahap etis, dan tahap religius [49,50]. Ketika tahap ini terjadi secara hirarkis yang menunjukkan tahap religiusitas yang mengakar pada eksistensi. Eksistensi menurutnya, merupakan realisasi diri tertinggi sebagai makhluk rohani.

\section{The Aesthetic Stage}

Kierkegaard menunjuk kepada nature of human sebagai makhluk sensual (inderawi). Spiritualitas pada tahap ini merupakan tahap yang mengharapkan dijauhkan dari penderitaan dan diberikan kesenangan [51]. Spritualitas diberdayakan dalam mengatasi dorongan-dorongan dasar. Pertimbangan spiritualitas pada tahap ini bersandar pada kepuasan, frustrasi, rasa nikmat, sakit, susah, ekstasi estetis, dan putus asa. Jika gagal melewati tahap ini, maka yang ada keputusasaan terhadap yang Rohani dan titik ekstremnya adalah suicide.

\section{The Ethic Stage}

Pada tahap ini, Kierkegaard menunjukkan bahwa seseorang mulai memperhitungkan standar-standar universal [49,50,52]. Eksistensi spiritual memancar kepada the other, bagaimana memperlakukan orang lain, dan alam. Moralitas menjadi landasan hidupnya. Ada penyelerasan diri terhadap norma bersama untuk tujuan yang lebih tinggi. Aturan-aturan agama memainkan peran pada tahap ini. Kepatuhan akan aturan, menghindari pelanggaran-pelanggaran menjadi eksplisit pada tahap ini. Kesalehan sosial juga biasanya tampak pada tahap ini. Pertimbangan rasio, suara hati dan refleksi mulai memainkan peranan penting dalam memberikan bentuk dan konsistensi pada kehidupan.

\section{The Religious Stage}

Secara sederhana dapat dikatakan bahwa kesadaran akan keputusasaan membuat individu insaf bahwa ia tidak dapat mengandalkan diri sendiri dan kekuatannya sendiri. Individu merasa dirinya kecil dan tak berdaya sambil mendambakan topangan dan bantuan dari kekuatan adi-manusiawi. Kekuatan adi-manusiawi yang dimaksudkan di sini adalah Allah sendiri. la menjadi pusat penyerahan diri individu dan penyerahan diri itu bersifat tanpa syarat. Penyerahan diri tanpa syarat ini didasarkan pada keyakinan penuh bahwa Allah-lah satu-satunya pegangan terakhir yang memberi rasa aman dan pengharapan bagi manusia [50].

Kierkegaard mengatakan bahwa "diri dalam keadaan sehat dan bebas dari keputusasaan hanya ketika, tepatnya dalam keputusasaan, diri itu bertumpu secara transparan pada Allah" [49]. Itu berarti Allah dilihat sebagai tumpuan hidup manusia dan barangsiapa yang membuka diri terhadapNya akan memperoleh jaminan pembebasan dan keselamatan [53].

Dengan kata lain, manusia yang ingin bebas dari situasi yang membelenggu dirinya dituntut untuk menerima Allah dengan penuh keterbukaan dan penyerahan diri yang total. Dalam tahap ini, individu yakin bahwa Allah dapat menghapus penderitaan dan keputusasaannya. Bila individu tiba pada situasi ini maka itulah yang disebut sebagai loncatan kepercayaan(the leap of faith) $[50,53]$. Bagi Kierkegaard, satu-satunya cara 
atau jalan untuk sampai kepada Allah adalah kepercayaan atau iman(faith). Dengan loncatan kepercayaan atau iman (the leap of faith), seorang individu akan dihantar untuk berhadapan dengan Subyek Allah. Maksudnya bahwa Allah hanya dapat dijumpai melalui subjektivitas dalam kedalaman batin personal dan bukan melalui jalan objektif-rasional.

Allah tak dapat dijelaskan dengan patokan akal budi manusia. Bagi Kierkegaard, tak ada satu pun konsep rasional yang dapat menjelaskan relasi Allah dan manusia yang unik dan amat subjektif itu. Kierkegaard mengatakan bahwa bagi Allah, apa yang tidak terpikirkan dan apa yang paling tidak diharapkan bisa saja terjadi. Hal ini hanya dapat dipahami melalui kaca mata iman. Iman selalu bersifat tidak rasional dan berawal pada saat pikiran berhenti [51,52]. Dengan demikian, iman (faith) memainkan peranan sentral dalam eksistensi tahap religius. Individu, dalam tahap ini, mengambil keputusan mengenai sikap dan perilakunya tidak berdasarkan atas keinginan sensual, tidak pula sesuai norma universal yang berlaku tetapi berlandaskan pada iman atau kepercayaannya pada Allah.

Berdasarkan ketiga tahap yang ditawarkan oleh Kierkegaard di atas, tahap tertinggi eksistensi manusia adalah ketika ia mencapai tahap religius. Pada perspektif life span development, tahap ini banyak ditemui pada usia senja (lansia) yang hampir seluruh aktivitas yang mengandalkan skill, kognitif, fisik, sudah dilaluinya pada masa-masa sebelumnya, termasuk pada masa dewasa yang diindentikkan dengan masa kesuksesan.
Terang benderang dari penjelasan di atas, bahwa stigma negatif terhadap lansia memang sudah mengandung diskriminasi yang sangat jelas. Hidup sebagai life span development mengandung banyak dinamika yang tidak dapat diukur dengan garis linier. Terbukti dalam konteks ini adalah spiritualitas. Kearifan puncak manusia justru berada pada masa ini $[54,55]$.

\section{3 | Tugas-Tugas Perkembangan Spiritual Lansia Perspektif Psikologi Islam}

Pada bagian sebelumnya telah diuraikan secara ringkas tahap-tahap perkembangan spiritual manusia dalam rentang kemewaktuannya, termasuk dalam hal ini adalah lansia. Oleh karena itu, pada bagian terakhir ini akan dicoba merumuskan tugas-tugas perkembangan spiritual atau bagaimana cara mengaktualisasikan spiritual yang baik. Pendekatan yang akan dipakai adalah pendekatan integratif Psikologi Islam. Pendekatan psikologi Islam bukan untuk menyempitkan atau mengalihkan kajian psikologi perkembangan ke wacana agama. Namun, justru pendekatan tersebut disajkan semata-mata dengan tujuan menginsyafi fenomena Lansia (aging/ending) dan spiritualitas dalam satu tarikan nafas. Keluasan makna kata tersebut beserta implikasinya mengakar kuat pada tradisitradisi agama dan spiritualitas hari ini. Pendekatan yang interdisipliner dalam meneropong perkembangan manusia sangat relevan, mengingat hari-hari ini kajian dari psikologi perkembangan cenderung linier yang justru menyempitkan makna perkembangan manusia. 
Kata al-ashr memiliki salah satu makna yang identik dengan span of lifetime. Konteks lansia jika dikaitkan dengan term ini, hampir melewati $2 / 3$ dari rentang masa hidup manusia. Oleh karenanya, masa kehidupan lansia merupakan suatu ashr. Oleh beberapa teorisi teori perkembangan, kerapkali masa ini dikaitkan dengan tema kedukaan, keterlemparan dan kematian [18]. Sebaliknya, spiritualitas pada lansia biasanya mengalami apa yang disebut Maslow dengan peak experience [56].

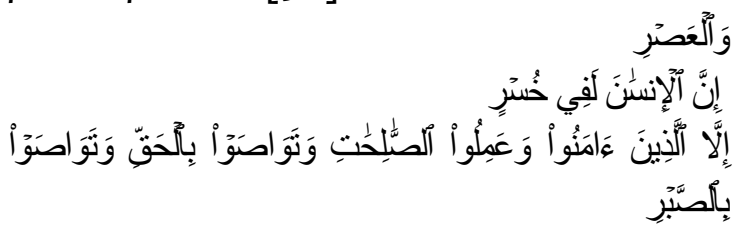

"Demi Masa. Sungguh manusia berada dalam kerugian yang amat banyak. Kecuali, orang-orang yang beriman, beramal soleh, dan saling mewasiatkan dalam kebenaran dan saling mewasiatkan dalam kesabaran".

Kata (العصر)al-'ashr berasal dari kata (عرر) 'ashara yang secara bahasa berarti menekan sesuatu sehingga apa yang terdapat pada bagian terdalam dari padanya nampak ke permukaanataukeluar (memeras) [57]. Berkaitan dengan lansia kata 'ashr dapat dinisbatkan kepada waktu 'ashr dari life span development.

Kemudian, kata (الإنسان)al-insan/ manusia berasal dari akar kata yang dapat berarti bergerak atau dinamisme, lupa, merasa bahagia (senang) [57]. Ketiga arti ini menggambarkan sebagian dari sifat serta ciri khas psikologis manusia. Adapun kata (خسر) khusr mempunyai banyak arti, antara lain rugi, sesat, celaka, lemah, tipuan dan sebagainya yang kesemuanya mengarah kepada makna-makna negatif, atau tidak disenangi oleh siapa pun [57].
Pada tinjauan psikologi perkembangan, terutama yang berkaitan dengan perkembangan spiritual, ayat ini menggambarkan Allah bersumpah atas nama 'ashr, yaitu masa rentang hidup manusia. Selain itu, dapat dimaknai juga masa senjanya kehidupan manusia, dimana pada pembahasan sebelumnya masa 'ashr ini sebenamya puncak spiritualitas manusia. Selanjutnya, disebutkan bahwa semua manusia diliputi oleh kerugian yang besar dan beraneka ragam. Kecuali melaksanakan tugas-tugas perkembangan spiritualnya baik individual maupun sosial, yaitu:

\section{Beriman kepada Allah}

Ulama membagi ajaran agama kepada dua sisi, yakni pengetahuan dan pengamalan. Akidah yang wajib diimani merupakan sisi pengetahuan, sedang syariat merupakan sisi pengamalan. Atas dasar ini, para ulama memahami النين امنو (orang yang beriman)dalam arti orang-orang yang memiliki pengetahuan menyangkut kebenaran. Puncak kebenaran adalah pengetahuan tentang ajaran-ajaran agama yang bersumber dari Allah [57].

Orang yang beriman diibaratkan dengan kagum dan cinta, dimana selalu ada tanya dan gejolak. Ada harapan mengenai cintanya dibalas, ada juga rasa takut tidak kesampaian. Singkatnya, tugas perkembangan spiritual ini adalah bagaimana menggantung diri dan pembenaran melalui hati terhadap yang Ilahi.

2. Beramal shaleh

$$
\text { Kata (عل) 'amall tindakan }
$$
(58), digunakan oleh al-Qur'an untuk menggambarkan penggunaan daya manusia 
(daya pikir, fisik, qalbu, dan daya hidup yang dilakukan dengan sadar oleh manusia dan jin.

Kata (صا J) shalih terambil dari kata (صلح) shaluha al-Qur'an sering dijelaskan sebagai lawan dari kata (فاسد)faasid/ rusak. kata shalih diartikan sebagai tiadanya (terhentinya) kerusakan, dapat juga diartikan bermanfaat dan sesuai [57]. Baik dalam hal ini adalah baik bentuk konkritnya juga baik dalam motif (niat).

Dengan demikian, lebih jauh kita dapat berkata bahwa di sisi Allah, nilai suatu pekerjaan bukan semata-mata dari bentuk lahiriah yang tampak di alam nyata, tetapi yang lebih penting adalah niat pelakunya. Dengan demikian, tugas perkembangan 2/4 telah dilakukan.

\section{Saling wasiat-mewasiatkan dalam Kebenaran}

Kata (تواصوا)tawaashau berasal dari kata (وصى)washaa, (وصية) washiilyatanyang secara umum diartikan sebagai menyuruh secara baik. Kata ini berasal dari kata (رض ardh waashiyahyang berartitanah yang dipenuhi atau berkesinambungan tumbuhannya. Berwasiat adalah tampil kepada orang lain dengan kata-kata yang halus agar yang bersangkutan bersedia melakukan sesuatu pekerjaan yang diharapkan dari padanya secara bersinambung [57]. Kata-kata wasiat adalah kata-kata yang halus dan lemah lembut sehingga menumbuhkan, merawat, bahkan menjaga dengan baik dan ikhlas.

4. Saling wasiat-mewasiatkan dalam
kesabaran
Ketika dalam saling mewasiatkan/nasehat ditemui kendala, maka kesabaran menjadi kunci. Shabr secara bahasa artinya menahan, baik gejolak hawa nafsu atau apapun untuk tujuan yang lebih baik [57]. Berkaitan dengan perkembangan spiritual lansia, maka saling berbagi pengalaman yang dapat menginspirasi bagi orang yang lebih muda dapat meningkatkan kualitas spiritualnya. Namun, dalam saling mengingatkan tersebut, hendaknya memakai kata-kata halus dan kesabaran sehingga bagi si pendengar layaknya mendapat sebuah "hadiah".

Jika keempat tugas perkembangan ini dilaksanakan dengan baik, maka secara spiritual masa ashr dalam hidup kita tidak sebagai orang berada dalam kerugian. Imam Syafi'i pernah berkata bahwa seandainya tidak ada lagi surah yang turun setelah al-ashr, maka itu sudah cukup sebagai jalan bagi manusia, terutama masa senja untuk dapat bahagia di dunia dan di akherat.

\section{5 | PENUTUP}

Perkembangan manusia merupakan life span development. Begitu juga dengan perkembangan spiritual pada lansia. Perkembangan spiritual ini tidaklah seperti garis lurus yang linier seperti pengandaian pada perkembangan fisik. Spiritual selalu dinamis bahkan enigmatik karena hanya secuil saja yang dapat disentuh oleh kajiankajian ilmiah kontemporer. Oleh karenanya, mendekati subjektivitas spiritual pada lansia haruslah lebih bercorak eksistensial. Hal ini mengingatkan kita bahwa religiusitas itu unik.

Agama dan spiritualitas bagaikan tubuh dan jiwa walaupun religiusitas atau spiritualitas berbeda dengan agama dalam penghayatannya. Agama lebih merupakan aturan-aturan umum yang formal mengatur 
kehidupan secara universal. Akan tetapi, spiritual merupakan peculiar mine, ia unik pada diri subjek penghayatnya.

Terlebih lagi, pada lansia, spiritualitas menemukan cahaya kemilaunya. Pada masa lansia ini, ketergantungan kepada yang material lebih berkurang. Hal ini memberikan kesempatan kepada yang lebih bernuansa spiritual dan Ilahi untuk hadir dalam ruangruang keintiman yang ekslusif.

Pada masa ini, yang llahi menampakkan diri dalam kejernihan hati al-ashr yang bergelora, yang merindu dan mendamba. Keintiman, kehangatan nuansa spiritualistik akan memenuhi dan mengisi hari-hari usia senja ini. Betapa irinya mereka yang belum mencapai usia ini. Betapa cemburunya orangorang yang tidak dapat merasakan usia ini. Akan tetapi, bagaimanapun juga, seperti yang terkandung dalam kata al-ashr, usia ini justru membuat terjatuh kepada kerugian yang sangat besar apabila kejernihan dan kehangatan spiritual tidak mampu dicerap dengan kalbu yang bersih. 


\section{Daftar Pustaka}

[1]. Ziegenhain P. The Politics and Policies of Population Change in Indonesia and Malaysia. AEI Insights: An International Journal of Asia-Europe Relations. 2019;5(1):57-72.

[2]. Lloyd-Sherlock P. Living longer: Ageing, development and social protection. Zed books; 2004.

[3]. Badan Pusat Statistik. Statistik Penduduk Lanjut Usia 2019 [Internet]. Jakarta: Badan Pusat Statistik; 2020 [dikutip 8 Maret 2021]. Tersedia pada: https://www.bps.go.id/publication/2019/ 12/20/ab17e75dbe630e05110ae53b/statis tik-penduduk-lanjut-usia-2019.html

[4]. Fernández-Niño JA, Bonilla-Tinoco LJ, Manrique-Espinoza BS, RomeroMartínez M, Sosa-Ortiz AL. Work status, retirement, and depression in older adults: An analysis of six countries based on the Study on Global Ageing and Adult Health (SAGE). SSM-population health. 2018;6:1-8.

[5]. Mahwati Y. The relationship between spirituality and depression among the elderly in Indonesia. Makara Journal of Health Research. 2017;13-9.

[6]. Tim Redaksi. Kemenag Sebut 63 Persen Jemaah Haji Tahun Ini Lansia. CNN Indonesia. Nasional. 24 April 2019;

[7]. Malone J, Dadswell A. The role of religion, spirituality and/or belief in positive ageing for older adults. Geriatrics. 2018;3(2):28.

[8]. Thauvoye E, Vanhooren S, Vandenhoeck A, Dezutter J. Spirituality and well-being in old age: exploring the dimensions of spirituality in relation to late-life functioning. Journal of religion and health. 2018;57(6):2167-81.
[9]. Clark CC, Hunter J. Spirituality, spiritual well-being, and spiritual coping in advanced heart failure: Review of the literature. Journal of Holistic Nursing. 2019;37(1):56-73.

[10]. Janssen-Niemeijer A, Visse M, Van Leeuwen R, Leget C, Cusveller B. The role of spirituality in lifestyle changing among patients with chronic cardiovascular diseases: a literature review of qualitative studies. Journal of religion and health. 2017;56(4):1460-77.

[11]. Datta S, Newberg A. The relationship between the brain and spirituality with respect to aging and neurodegenerative diseases: clinical and research implications. Journal of Religion, Spirituality \& Aging. 2020;32(4):357-80.

[12]. Dorji N, Dunne MP, Seib C, Deb S. Quality of life among senior citizens in Bhutan: Associations with adverse life experiences, chronic diseases, spirituality, and social connectedness. Asia Pacific Journal of Public Health. 2017;29(1):35-46.

[13]. MacKinlay E, Burns R. Spirituality promotes better health outcomes and lowers anxiety about aging: The importance of spiritual dimensions for baby boomers as they enter older adulthood. Journal of Religion, Spirituality \& Aging. 2017;29(4):24865.

[14]. Zanjari N, Sani MS, Chavoshi MH, Rafiey H, Shahboulaghi FM. Successful aging as a multidimensional concept: An integrative review. Medical journal of the Islamic Republic of Iran.

2017;31:100.

[15]. Burman E. Deconstructing Developmental Psychology. New York: Taylor \& Francis; 2016. 
[16]. Braun V, Clarke V. Using thematic analysis in psychology. Qualitative Research in Psychology. 1 Desember 2006;3(2):1-41.

[17]. Walter T. What Death Means Now: Thinking Critically about Dying and Grieving. London: Policy Press; 2017. $144 \mathrm{hlm}$.

[18]. Santrock J. Life-Span Development. 17th ed. New Jersey: McGraw-Hill; 2019.

[19]. Lee SB, Oh JH, Park JH, Choi SP, Wee $\mathrm{JH}$. Differences in youngest-old, middle-old, and oldest-old patients who visit the emergency department. Clin Exp Emerg Med. 31 Desember 2018;5(4):249-55.

[20]. Goulet LR, Baltes PB. Life-Span Developmental Psychology: Research and Theory. New York: Academic Press; $2013.609 \mathrm{hlm}$.

[21]. Pickard S. This mortal life: ageing and spirituality after the Great Transition. Journal of Religion, Spirituality \& Aging. 3 April 2021;33(2):101-11.

[22]. Jafaripoor $\mathrm{H}$, Safarabadi $M$, Pourandish Y, Khanmohammadi A, Mohammad Aghaiepoor S, Rahbarian A, dkk. The Elders' Spiritual Well-Being and Their Quality of Life: A CrossSectional Study. Journal of ClientCentered Nursing Care. 10 Agustus 2018;4(3):145-54.

[23]. Khormaei F, Azadi Dehbidi F, HassanZehi E. Prediction of Death Anxiety Based On Demographic Characteristics and Spirituality Components in the Elderly. Health, Spirituality and Medical Ethics. 10 Juni 2017;4(2):21-6.

[24]. Shirkavand L, Abbaszadeh A, Borhani F, Momenyan S. Correlation between spiritual well-being with satisfaction with life and death anxiety among elderlies suffering from cancer. Electron J Gen Med. 19 Februari 2018;15(3).

[25]. Solaimanizadeh F, Mohammadinia N, Solaimanizadeh L. The Relationship Between Spiritual Health and Religious Coping with Death Anxiety in the Elderly. J Relig Health [Internet]. 1 Agustus 2020 [dikutip 13 Maret 2021];59(4):1925-32. Tersedia pada: https://doi.org/10.1007/s10943-01900906-7

[26]. Heidari M, Ghodusi Borujeni M, Kabirian Abyaneh S, Rezaei P. The Effect of Spiritual Care on Perceived Stress and Mental Health Among the Elderlies Living in Nursing Home. J Relig Health. 1 Agustus 2019;58(4):1328-39.

[27]. Straßner C, Frick E, Stotz-Ingenlath G, Buhlinger-Göpfarth N, Szecsenyi J, Krisam J, dkk. Holistic care program for elderly patients to integrate spiritual needs, social activity, and self-care into disease management in primary care (HoPES3): study protocol for a clusterrandomized trial. Trials [Internet]. 18 Juni 2019 [dikutip 13 Maret 2021];20(1):364. Tersedia pada: https://doi.org/10.1186/s13063-0193435-z

[28]. Corr CA. Elisabeth Kübler-Ross and the "Five Stages" Model in a Sampling of Recent American Textbooks. Omega (Westport). 2020;82(2):294-322.

[29]. Nitobe I. The Way of the Samurai. London: Arcturus Publishing; 2017. 84 hlm.

[30]. Matsumoto D, Juang L. Culture and Psychology. 6th edition. Boston. MA: Cengage Learning; 2016. $544 \mathrm{hlm}$. 
[31]. Spilka B. The Psychology Of Religion. New York: Routledge; 2019. $295 \mathrm{hlm}$.

[32]. Smith C. Religion: What It Is, How It Works, and Why It Matters. New Jersey: Princeton University Press; 2019. $292 \mathrm{hlm}$.

[33]. Shihab MQ. Menabur Pesan Ilahi: AlQur'an dan Dinamika Kehidupan Masyarakat. Jakarta: Lentera Hati; 2006.

[34]. Wasik MA. "Islam Agama Semua Nabi" Dalam Perspektif Al-Qur'an. ESENSIA: Jurnal IImu-IImu Ushuluddin [Internet]. 1 Oktober 2016 [dikutip 13 Maret 2021];17(2):225-34. Tersedia pada: http://ejournal.uinsuka.ac.id/ushuluddin/esensia/article/vi ew/1289

[35]. Streib H, Hood RalphW. Semantics and Psychology of Spirituality. A CrossCultural Analysis. New York: Springer; 2016.

[36]. Harris KA, Howell DS, Spurgeon DW. Faith concepts in psychology: Three 30-year definitional content analyses. Psychology of Religion and Spirituality. 2018;10(1):1-29.

[37]. Pargament KI, Magyar-Russell GM, Murray-Swank NA. The sacred and the search for significance: Religion as a unique process. Journal of Social Issues. 2005;61(4):665-87.

[38]. Al-Iskandari IA. Syarh Al-Hikam Ibnu A'thaillah Al-Iskandari. (syarh.) Syeikh Abdullah Asy-Syarkawi al-Khalwati. Jakarta: Turos Pustaka; 2014.

[39]. Gulen MF. Tasawuf Untuk Kita Semua. Jakarta: Republika; 2014.

[40]. Romadhon S. Sosiologi Spiritualitas \& Kesalehan Sosial. Spiritualita. 2020;4(2).
[41]. Jones JW. Living Religion: Embodiment, Theology, and the Possibility of a Spiritual Sense. Cambridge: Oxford University Press; 2019.

[42]. Alatas IF. Al Rashafat. Yogyakarta: Bentang Pustaka; 2013.

[43]. Al-Hujwiri AIU. Kasyful Mahjub. Bandung: Mizan; 1994.

[44]. Moberg DO. Aging and Spirituality: Spiritual Dimensions of Aging Theory, Research, Practice, and Policy. New York: Routledge; 2012.

[45]. Hamersma H. Filsafat Eksistensi Karl Jaspers. Jakarta: Gramedia; 1985.

[46]. Peach F. The Origins and Significance of Boundary Situations in Karl Jaspers' Existence Philosophy. The Origins and Significance of Boundary Situations in Karl Jaspers' Existence Philosophy. 2019;171-91.

[47]. Raynova YB. Philosophy between Power and Powerlessness: A Homage to Karl Jaspers. Labyrinth. 2019;21(1):167-87.

[48]. Heidegger M. Being and Time. New York: State University of New York; 1996.

[49]. Kierkegaard S. The Essential Kierkegaard. Princeton: Princeton University Press; 2000.

[50]. Tjaya TH. Kierkegaard dan pergulatan menjadi diri sendiri. Jakarta: KPG; 2004.

[51]. Kierkegaard S. Kierkegaard's Writings, XI: Stages on Life's Way. 1988;

[52]. Evans CS. Kierkegaard: an introduction. Cambridge: Cambridge University Press; 2009. 
[53]. Armawi A. Eksistensi Manusia dalam Filsafat Soren Kierkegaard.

Yogyakarta: Gadjah Mada University; 2011.

[54]. Brown C, Lowis MJ. Psychosocial development in the elderly: An investigation into Erikson's ninth stage. Journal of Aging Studies. 2003;17(4):415-26.

[55]. Winnicott D. Erik H. Erikson: Review of Childhood and Society 11965 . Dalam: Psycho-Analytic Explorations. Routledge; 2018. hlm. 493-4.

[56]. Mouton AR, Montijo MN. Love, passion, and peak experience: $A$ qualitative study on six continents. The journal of positive psychology. 2017;12(3):263-80.

[57]. Shihab MQ. Tafsir al-Mishbah: Pesan, Kesan, dan Keserasian al-Qur'an. Vol. 15. Jakarta: Lentera Hati; 2011.

[58]. Munawwir AW. عمل. Dalam: Kamus alMunawwir: Arab-Indonesia Terlengkap. Surabaya: Pustaka Progresif; 1984.

[59]. Aubrey RF. Historical development of guidance and counseling and implications for the future. Personnel \& Guidance Journal. 1977; 